Aoustin, E. ; Schäfer, A.I. ; Fane, A.G. ; Waite, T.D. (2001) Ultrafiltration of Natural Organic Matter, Separation and Purification Technology, 22-23, 63-78 doi:10.1016/S1383-5866(00)00143-X

\section{Ultrafiltration of Natural Organic Matter}

E. Aoustin ${ }^{1}$, A.I. Schäfer ${ }^{1}$, A.G. Fane ${ }^{1, *}$, T.D. Waite ${ }^{2}$

${ }^{1}$ UNESCO Centre for Membrane Science and Technology, School of Chemical Engineering and Industrial Chemistry, University of New South Wales, Sydney, NSW 2052, Australia

${ }^{2}$ School of Civil \& Environmental Engineering, University of New South Wales, Sydney, NSW 2052, Australia

*Corresponding author: A.Schaefer@unsw.edu.au; ph ++61 29385 4315; fax ++61 293855054

\section{Abstract}

Increasingly stringent regulations for drinking water quality have stimulated the application of ultrafiltration to water treatment. In addition to removing particulate materials from wate (including microorganisms, bacteria and viruses), the use of membrane treatment also meets purification requirements. However, irreversible fouling curtails the economic viability of such a process.

Experiments in stirred-cells were conducted to evaluate the effects of surface water composition on rejection and fouling of two ultrafiltration membranes with different molecular weight cut-offs $(10 \mathrm{kDa}$ and $100 \mathrm{kDa})$. Experimental solutions consisted of natural organic matter or humic substances in a background electrolyte.

The effect of calcium concentration decreased rejection of humic acid under certain circumstances This is believed due to reduced molecular size with an initial increase in calcium concentration. However, at about $2.5 \mathrm{mM} \mathrm{CaCl}$, IHSS humic acid aggregates. This aggregation increased rejection, and also caused irreversible fouling of the $100 \mathrm{kDa}$ membrane, presumably as a result of pore size reduction due to internal deposition of aggregates. This was confirmed by blocking law indicated the importance of a 'critical flux' effect.

The organics and their various fractions showed differences both in rejection and flux decline. The larger and more UV-absorbing fraction of humic acid was shown to be responsible for irreversible pore adsorption and plugging. The fulvic acid and the hydrophilic fraction showed a smaller and mostly reversible flux decline.

Keywords: Aggregation, Fouling, Humic Substances, Natural Organic Matter (NOM), Ultrafiltration.

\section{Nomenclature}

A Membrane area $\left(\mathrm{m}^{2}\right)$

$\mathrm{C}_{\mathrm{F}} \quad$ Feed concentration $\left(\mathrm{mgL}^{-1}\right)$

Bulk concentration (concentration in the batch cell) $\left(\mathrm{mgL}^{-1}\right)$

$\mathrm{C}_{\mathrm{P}} \quad$ Permeate concentration $\left(\mathrm{mgL}^{-1}\right)$

$\mathrm{C}_{\mathrm{R}} \quad$ Concentration in the cell at the end of the experiment $\left(\mathrm{mgL}^{-1}\right)$

$\mathrm{d}_{\text {particle }} \quad$ Particle diameter $(\mu \mathrm{m})$

$\mathrm{d}_{\text {pore }} \quad$ Pore diameter $(\mu \mathrm{m})$

$\mathrm{J}_{0} \quad$ Initial feed flux $\left(\mathrm{Lm}^{-2} \mathrm{~h}^{-1}\right)$

$\mathrm{k}_{\mathrm{CB}} \quad$ Complete blocking filtration constant (-)

$\mathrm{k}_{\mathrm{CF}} \quad$ Cake filtration filtration constant (-)

$\mathrm{k}_{\mathrm{IB}} \quad$ Intermediate blocking filtration constant (-)

$\mathrm{k}_{\mathrm{SB}} \quad$ Standard blocking filtration constant (-)

PWF $\quad$ Pure water flux $\left(\mathrm{Lm}^{-2} \mathrm{~h}^{-1}\right)$

Rej Rejection (\%)

$\mathrm{t}$ Time (h)

$\mathrm{V} \quad$ Total filtrate volume (L)

$V_{F} \quad$ Volume of feed $(\mathrm{mL})$

$\mathrm{V}_{\mathrm{Pi}} \quad$ Volume of permeate (sample i) $(\mathrm{mL})$

$V_{R} \quad$ Volume left in the cell at the end of the

D Percentage of solute or colloid deposited $(\%)$

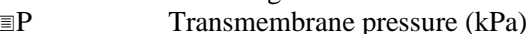

\section{Introduction}

Natural organic matter (NOM) is a complex matrix of organic compounds present in natural surface water sources. Not only does it affect the odour, colour and taste of water, it forms complexes with heavy metals and pesticides, and also reacts with chlorine, the most widely used oxidant for wate desinfection, to form chlorinated disinfection by-products (DBPs). The latter, such as trihalomethanes (THMs) and haloacetic acids (HAAs), have been (r) carcinogens. Alternative disinfectants, such as chloramines, chlorine dioxide or ozone are available, but are generally more expensive, less effective and also lead to the formation of DBPs [1] Recognising that chlorination will continue to be the most common disinfection process, removal of DBP precursors present in raw-water sources is a necessity for reducing the potential for chlorinated DBPs formation.

Several treatment processes or their combinations are capable of removing NOM from water Although UF has proved to be a valuable and effective technique in terms of removal efficiency, process complexity and cost, flux decline due to the adsorption and deposition of foulants is normally experic inever irreversible. Reversible fouling, cauced by solid accumulation on the menbrane sufface, is typically remedied by intermittent hydraulic backwashes. In comparison, irreversible fouling requires chemical cleaning of the membrane and limits the viability of UF as a water treatment process. The objective of this study is to understand the impact of different parameters on ultrafiltration of NOM under conditions typical of surface water. In particular, the influence of solution conditions including $\mathrm{pH}$, calcium concentration and type of organic are investigated, as well as operational parameters such as flux and membrane pore size. 


\subsection{Characteristics of NOM}

NOM is the main component of organic carbon in aquatic systems. It is a complex, difficult to separate mixture of similar macro-organic molecules, derived from the degradation and separate mixture of similar macro-organic molecules, derived from the degradation and
decomposition of biological organisms, with a broad spectrum of functional groups, sub-structures

and molecular weight distribution, strongly depending on its origin and genesis [2].

Fractions isolated from water by sorption on weak-base ion exchange (XAD) resins showed an average NOM composition of $10 \%$ humic acid (HA), 40\% fulvic acid (FA) and 30\% hydrophilic acid (Hyd) [3]. These fractions were characterised on the basis of their water solubility at a given $\mathrm{pH}$; FA remains in solution at low $\mathrm{pH}(<2)$, while $\mathrm{HA}$ is insoluble at this $\mathrm{pH}$, due to the small proportion of hydrophilic groups in these molecules $[3,4]$.

Some authors have characterised NOM in terms of molecular weight with results depending on NOM source and method. Apparent molecular weights (AMW) have been determined using UF fractionation. The separation of such macromolecules is based on their different molecular size and fractionation. The separation of such macromolecules is based on their different molecular size and
shape, allowing discrimination on appropriate UF membranes [5]. It appears that both FA and HA are relatively polydispersed mixtures, according to the results of Averret et al. [6] and Thurman et al. [7]. HS have a structure that varies with salt content, $\mathrm{pH}$ and concentration. At low HS concentrations with low concentration of salt, their structure is rather linear at $\mathrm{pH}$ values from 6.5 to 9.5. At high HS concentrations and with salt added, these natural materials form spherocolloida structures [8]. Jucker and Clark [5] also showed that the AMW distributions determined at low ionic strength are shifted towards higher AMW compared to results obtained at high ionic strengths. This phenomen is probaty phenomenon is probably due to the fact that humic substances (HS) are more compact at high ionic strength, as a result of a contraction of the molecule, which is caused by diminution of intramolecular electrostatic repulsion as the charged groups are neutralised [9]. Aster et al. [10] showed that at $\mathrm{pH} 7$, the AMW distributions are shifted towards smaller molecules, as compared to $\mathrm{pH}$ of 4 to 6 .

It is possible that the effect of fractionation, pressure and stirring on the molecular size distribution may lead to the separation of structural sub-units of NOM believed to be joined by H-bonds [11] However, results show that the molecular weight of FA is lower than that of HA, and FA has lower carbon content [9]. In general, the more hydrophilic the NOM, the lower is its AMW [12].

HS are known to be the most aromatic NOM fraction. HA and FA are anionic polyelectrolytes with carboxyl functional groups and phenolic groups. Titration depends on concentration, but results showed a greater phenolic content for HA than for FA $[1,5,6]$.

Tipping and Ohnstad [13] have studied the removal of HS from solution. The degree of complexation was found to increase with $\mathrm{CaCl}_{2}$ concentration, and above a concentration of $2.5 \mathrm{mM}$ of $\mathrm{CaCl}_{2}$, substantial aggregation occurred, at neutral or alkaline $\mathrm{pH}$. The explanation given is that the hydration of the molecule is diminished when its ionised functional groups are neutralised by complexation with $\mathrm{Ca}^{2+}$. When the degree of neutralisation is sufficiently high, the solubility is exceeded and the HS precipitates. According to these authors, the differences in extents of remova higher molecular weight HS have a greater content of complexing polar groups.

These different characteristics of the NOM and organic fractions were found to be relevant in UF membrane fouling.

\subsection{Rejection of NOM by UF membranes}

Retention by UF membranes depends on the molecular volume (and only indirectly on mass) and the physico-chemical characteristics of the organics [14]

Küchler and Miekeley [15] studied UF of humic compounds through $1 \mathrm{kDa}$ membranes. It was observed that HA retention (80-90\%) was greater than that of FA (60-70\%). They also observed observed that HA retention $(80-90 \%)$ was greater than that of FA $(60-70 \%)$. They also observed
that, since HA has a higher molecular mass and a smaller proportion of hydrophilic groups, it aggregates and precipitates, especially under high ionic strength and low $\mathrm{pH}$ conditions.
The results from Maartens et al. [16] showed that the NOM concentration in the permeate solutions decreased throughout the filtration period. This presumably occurred because of gradual pore closure throughout the filtration period. UV ratios showed that towards the end of the filtration period, only the smaller molecules passed through the membrane pores, a fact that indicates that the large molecules or large molecule complexes were adsorbed onto the membrane first, whereas the smaller ones remained in solution. From this result it could be concluded that there is a critical membrane pore size that will ensure effective removal of colour from natural waters.

\subsection{Rejection of multivalent ions by UF membranes}

Küchler and Miekeley [15] studied the retention of ionic compounds on a Amicon YM2 flat membrane (MWCO 2kDa). Salts containing monovalent anions, with small solvated ionic radii exhibited small retention and salts containing polyvalent anions exhibited high rejections. Similar effects were also observed by Staub et al. [14]. Fractionation experiments of natural waters have shown that some ions are partially retained during ultrafiltration, independent of the MWCO of the membrane. This selective retention is attributed to complexation with high molecular mass ligands [17].

\subsection{Membrane fouling by NOM}

Membrane fouling occurs through one or more of the following mechanisms: i) accumulation of solute and gradual irreversible changes to the polarised layer (such as cake formation), ii) surface adsorption/deposition of solutes and iii) adsorption/deposition of solute within the membrane. There are many factors contributing to fouling including surface properties (chemistry, morphology, etc.), hydrodynamic conditions, ionic strength and solute concentration [18].

Direct adsorption measurements of HS onto hydrophobic UF membranes were carried out by Jucker and Clark [5]. Adsorption decreased with increasing hydrophilicity and decreasing zeta potential. and Clark [5]. Adsorption decreased with increasing hydrophilicity and decreasing zeta potential.
Moreover, upon adsorption of HS, the membrane becomes more hydrophilic and apparent pore Moreover, upon adsorption of HS, the membrane becomes more hydrophilic and apparent pore
charge becomes less negative. They showed that adsorption of HA is greater than that of FA. This is due in part to the lower solubility of HA (HA is somewhat more hydrophobic than FA), and also to the fact that HA molecules might have more attachment sites and therefore binding to the membrane surface could be enhanced [13]. However, adsorption kinetics are faster for FA than for HA, mainly because the diffusivity is greater for small molecules than for large ones [19]. Kinetic studies by Maartens et al. [16] showed that adsorption of HA was slower than that of NOM. Also, adsorption is greater at $\mathrm{pH} 7 \mathrm{because}$ the charge on HS is less negative: there is less repulsion among adsorbing molecules and charge repulsion between the negat the HS molecule is lowered. Adsorption experiments showed an increase in adsorption with increasing calcium concentration. Calcium has been reported to screen lateral electrostatic repulsion in the adsorbed layer. For HA, calcium was adsorbed in proportion to the amount of HA adsorbed, which suggest it acts as a bridge between the membrane surface and the negatively charged HA molecules, and/or in between the negatively charged carboxyl groups which are not in contact with the membrane [20]. For FA, there seems to be competition between FA and calcium for the adsorption sites on the membrane surface. Finally, adsorption of HS tends to continue after the pore zeta potential reaches a plateau value. This suggests that the membrane pores are filled preferentially during adsorption, perhaps because they are higher energy adsorption sites. The continued adsorption after the zeta potential has reached the plateau can presumably be accounted for by uptake on the membrane skin. This could also indicate that adsorption might only be an initial phenomenon, after which deposition would be due to precipitation or aggregation. Precipitation and aggregation effects in the membrane boundary layer were reported to be important phenomena in nanofiltration [21].

In general, the extent of irreversible fouling with proteins, polysaccharides and NOM, has been found to be greater around the isoelectric point of the molecules, at high ionic strength, in solutions supersaturated with calcium, and on hydrophobic membranes [22-24]. 
Crozes et al. [25] investigated the effect of membrane hydrophilicity and organic compound polarity on fouling and stated that hydrophobic compounds appeared to be the principal foulant material. They also showed that the adsorption of low molecular weight molecules, smaller than the membrane pore size, could lead to significant irreversible fouling. The study also revealed that hydrophilic membranes were better suited for filtration of surface waters. Nilson and DiGiano [26] also found that hydrophobic NOM caused severe permeate flux decline compared to hydrophilic compounds.

Crozes et al. [27] also showed that the momentary accumulation of particulate or organic matter on the membrane surface does not necessarily lead to irreversible fouling of the membrane. Irreversible the membrane surface does not necessarily lead to irreversible fouling of the membrane. Irre

Chang and Benjamin [28] suggested that, when the membrane rejects a portion of the NOM, it remains near the membrane surface, so its concentration is higher near the surface than in the bulk solution (this phenomenon is called concentration polarisation (CP)). If the solubility of the NOM is exceeded in the CP layer, the NOM may form a new phase on the membrane surface, thereby increasing the hydraulic resistance across the membrane and limiting the permeate flux (the form and composition of the condensed phase is though to be a gel). Lahousine-Turcaud [29] suggested that backtransport of humic substances away from the membrane (by diffusion) was not great enough to overcome convective transport towards the membrane, so a layer of humic material accumulated near the membrane surface. The extent of convective transport depends on flux and thus indirectly on membrane pore size

Ravindran and Badriyha [30] as well as Lâné et al. [24, 31] suggested that concentration polarisation effects lead to surface fouling of the membrane due to the deposition of rejected solutes, and are generally reversible. On the other hand, internal pore fouling of the membrane caused by the adsorption of macromolecules is often irreversible [5 and 32]. Crozes et al [27] also demonstrated that parameters, such as flux, concentrate velocity, backwash frequency and transmembrane pressure could be adjusted to limit irreversible membrane fouling: this stresses the role of concentration polarisation in enhancing fouling.

In accord with earlier studies [33], fluxes reported by Maartens et al. [16] showed a sharp decline in the first few minutes of filtration. This was followed by a steadier decline during the later stages of the filtration process. This slower decline was ascribed to concentration polarisation and/or foulan adsorption from the filtration solution onto the membrane surfaces and pores. Indeed, changes in feed were much smaller, indicating that foulant adsorption was saturating and mainly occurred during the initial stages of filtration. The authors assumed that during the initial period, substances adsorbed onto the membrane to form a foulant layer dependent on the shear stresses from the crossflow velocity, which prevented further incess clear analysis that confirmed the fouling mechanism was not carried out by these authors.

Thus, the association of NOM with the membrane matrix, membrane pore blockage and plugging, precipitation, deposition, and surface layer formation are the factors contributing to the fouling mechanisms and the resulting flux decline. These factors are confounded by one another and are difficult to separate. This study attempts to distinguish between different mechanisms such as CP, gel or cake formation on the membrane surface, pore blocking and pore adsorption.

\section{Materials and methods}

\subsection{Membranes}

The membranes used in this study were flat-disc ultrafiltration membranes of the Millipore (Bedford, USA) PL-series. They are asymmetric regenerated cellulose membranes, with a propylene support, and are considered hydrophilic in nature.

Membranes of MWCOs of $10 \mathrm{kDa}$ and $100 \mathrm{kDa}$ were chosen. The pore sizes based on Dextran molecules retained were calculated after Worch [34] and are listed in Table 1. The surface charges of the membranes were measured and zeta potentials of the membranes are also summarised in
Table 1, together with other membrane characteristics such as average pure water flux, membrane permeability, and resistance.

The membranes are pre-treated with glycerine by the manufacturer to prevent drying. To remove it, $1 \mathrm{~L}$ of Milli-Q water was pre-filtered through the membranes, and the permeate was analysed with UV absorbance and TOC measurement to make sure all contamination was removed. The pure water flux (PWF) was measured prior to each experiment to evaluate membrane performance and a new membrane was used for each experiment.

\subsection{Filtration protocol}

All experiments were carried out in a magnetically stirred batch cell (volume of $110 \mathrm{~mL}$ and membrane area of $15.2 \cdot 10^{-4} \mathrm{~m}^{2}$ ) pressurised with high purity nitrogen gas and stirred at $270 \mathrm{rpm}$ (measured with a Philips PR 9115/00 stroboscope). A feed reservoir of $1.5 \mathrm{~L}$ was connected to the stirred cell to provide extended filtration volumes. Permeate was collected on a PC-controlled electronic balance.

The $10 \mathrm{kDa}$ and $100 \mathrm{kDa}$ membranes underwent different filtration protocols.

For the $10 \mathrm{kDa}$ membrane, $250 \mathrm{~mL}$ of feed solution were prepared and $25 \mathrm{~mL}$ were sampled. $225 \mathrm{~mL}$ of feed solution were introduced into the reservoir. Pressure was adjusted to $300 \mathrm{kPa}$ and the filtration cell was filled up by removal of air through the pressure valve. $150 \mathrm{~mL}$ of permeate were filtered into 3 sample vials of $50 \mathrm{~mL}$ each. The $75 \mathrm{~mL}$ of retentate were then also sampled for analysis. For the $100 \mathrm{kDa}$ membrane, $500 \mathrm{~mL}$ of feed solution were prepared and $50 \mathrm{~mL}$ were sampled. $450 \mathrm{~mL}$ of feed solution were introduced in the reservoir. Pressure was adjusted to $100 \mathrm{kPa}$ and the filtration cell was filled up. The permeate was sampled and then recycled into the reservoir together with the retentate. Filtration was repeated two more times. This recycling experiment enabled the separation of concentration polarisation effects from fouling effects. The $110 \mathrm{~mL}$ of retentate were then also sampled.

Volumes were calculated in order to have a 3-fold concentration in the cell after the experiment, assuming $100 \%$ rejection.

In order to determine the extent of irreversible fouling, Milli-Q water was filtered through the membrane, at the same operating pressure, after each experiment. Approximately $300 \mathrm{~mL}$ and $1000 \mathrm{~mL}$ were flushed for the $10 \mathrm{kDa}$ and $100 \mathrm{kDa}$ membranes, respectively.

\subsection{Stock Solutions}

Natural organic matter (NOM)

Two purified and well characterised organics, purchased from the International Humic Substances society (IHSS), Suwanee River Reference material, humic (IHSS HA) and fulvic acid (IHSS FA) were used. A third organic type, an Australian natural organic matter (NOM) was concentrated from Mooney Mooney Dam (Gosford, NSW, Australia) using microfiltration and reverse osmosis to concentrate all surface water constituents. The concentrate was further freeze-dried [35]. The NOM powder obtained includes all inorganic salts and hydrophilic organics, which are part of the surface water. However, organics, which are associated with particulates, are lost and concentration of sal is a drawback. It is, however important to use organics from an aqueous rather than soil origin due to the importance of the characteristics of the organics. Adsorption on XAD resins was chosen to to the importanc obtain three fractions of this NOM of different hydrophobicity, a humic acid fraction (NOM-HA), a fulvic acid fraction (NOM-FA) and a hydrophilic fraction (NOM-Hyd). The apparent molecul size of these fractions is reported elsewhere [35], but relevant results are summarised in Table 2. Chemicals

The chemicals used were of analytical grade and supplied by Ajax Chemicals, Australia. Milli-Q water of a quality superior than $18 \mathrm{M} \Omega / \mathrm{cm}$ was used for all solution preparations and experiments. Solution preparation

The synthetic surface water prepared contained a background electrolyte of $0.5 \mathrm{mM} \mathrm{CaCl}_{2}, 1 \mathrm{mM}$ $\mathrm{NaHCO}_{3}$, and $20 \mathrm{mM} \mathrm{NaCl}$. Solutions contained $12.5 \mathrm{mgL}^{-1}$ organic carbon (as DOC). This concentration, higher than the average content of typical surface water, was chosen to accelerate 
fouling. The desired calcium concentration was adjusted using a solution of $20 \mathrm{mM} \mathrm{CaCl}_{2}$. $\mathrm{pH}$ was adjusted to 7-8 and solutions were stirred for $1 \mathrm{~h}$ at $270 \mathrm{rpm}$ prior to the experiments.

\subsection{Analytical methods}

Dissolved organic carbon (DOC)

Because of its high carbon content $(=50 \%)$, total organic carbon (TOC) is considered a quantitative measurement of NOM. The samples were analysed using a Skalar 12 Carbon Analyser. TOC and DOC are used interchangeably in this study.

UV/Vis spectrometry (UV)

The presence of unsaturated compounds (substances with delocalised electrons) usually imparts a distinct colour to the contaminated water, and ultraviolet/visible (UV/Vis) light-spectroscopy can therefore be used to estimate the absorbing compounds concentration. This strong light absorption at short wavelength can be attributed to the benzoide bands of carboxyphenols present in organics. UV/VIS spectrometry was carried out using a Varian Cary 1E UV/VIS. Each sample was scanned from 190 to $500 \mathrm{~nm}$, the waved measured against a Milli-Q water reference without $\mathrm{pH}$ adjustment, following the suggested standard method for surface water analysis [36]. Contrary to DOC, the UV absorbance depends on organic type and is not a reliable method of concentration determination if the samples are modified during treatment

Inductively Coupled Plasma Atomic Emission Spectroscopy (ICP-AES)

A Perkin Elmer Optima 3000 Instrument was used to determine calcium iron content of the samples. Solutions were diluted at a 1:1 ratio with $4 \%$ nitric acid.

\subsection{Calculation}

Membrane flux was calculated as

$$
\mathrm{J}=\frac{1}{\mathrm{~A}} \frac{d \mathrm{~V}}{d \mathrm{t}}
$$

where $\mathrm{A}$ is the membrane area and $\mathrm{V}$ the permeate volume at time $\mathrm{t}$. The flux behaviour is given as the ratio of the flux after a volume $\mathrm{V}$ of permeate collected $(\mathrm{J})$ to the initial flux at the beginning of the experiment $\left(\mathrm{J}_{0}\right)$

Rejections were calculated by equation (2)

$$
\operatorname{Rej}=100 \cdot\left(1-\frac{\mathrm{C}_{\mathrm{P}}}{\mathrm{C}_{\mathrm{B}}}\right)
$$

where $C_{B}$ is the bulk concentration (concentration in the batch cell) and $C_{P}$ the permeate concentration.

Mass balance was used to determine the amount of deposit of solute as mass (in $\mathrm{mg}$ ) on the membranes as described by

$$
\mathrm{M}=\left(\mathrm{V}_{\mathrm{F}} \cdot \mathrm{C}_{\mathrm{F}}-\sum \mathrm{V}_{\mathrm{P}_{\mathrm{i}}} \cdot \mathrm{C}_{\mathrm{P}_{\mathrm{i}}}-\mathrm{V}_{\mathrm{R}} \cdot \mathrm{C}_{\mathrm{R}}\right) / 1000
$$

were $V_{F}$ is the volume of feed, $V_{P i}$ the volume of permeate $i$ and $V_{R}$ the volume left in the cell at the end of the experiment. $C_{F}$ is the feed concentration and $C_{R}$ the concentration in the cell at the end of the experiment. This can also be described as percent of mass in feed solution deposited

$$
\mathrm{D}=100 \cdot \frac{\mathrm{M}}{\mathrm{V}_{\mathrm{F}} \cdot \mathrm{C}_{\mathrm{F}}}
$$

The results for DOC must be treated with care, as the error is expected to be large, especially at low concentrations due to the analytical method used and risk of contamination of the samples.

\section{Results and discussion}

\subsection{Effect of calcium concentration}

The influence of calcium concentration on IHSS HA rejection and flux decline through both membranes was studied, with calcium concentration in the range of 0.5 to $4 \mathrm{mM}$. Results for flux and rejection are shown in Figure 1 and Figure 2, respectively.

There is negligible flux decline throughout the filtration experiment for the $10 \mathrm{kDa}$ membrane (Figure 1) as compared to the initial flux (dotted lines). Compared with the 100kDa membrane, the filtrate volume is much smaller, however, experiments repeated with the same volume as the $100 \mathrm{kDa}$ membrane did not show any flux decline either (see Figure 3). In fact, there is a slight increase of flux to $116 \%$ for $0.5 \mathrm{mM} \mathrm{Ca}$, even after the pure water flush of the membrane (113\%) This suggests that the IHSS HA renders the membrane more hydrophilic, as suggested by Jucker and Clark [5].

As shown in Figure 2A, rejection of IHSS HA calculated as DOC is in the range of 74 to $87 \%$ on the $10 \mathrm{kDa}$ membrane. This range of rejection was also confirmed by fractionation experiments [35], in the absence of calcium. Rejection is highest at $0.5 \mathrm{mM} \mathrm{Ca}$ and then decreases with calcium concentration up to $2.5 \mathrm{mM}$. This is probably due to the fact that, as charge repulsion between ionised negative groups on HA is lowered (by the positive charges of $\mathrm{Ca}^{2+}$ ), the molecules tend to curl up, and thus have a smaller molecular size, and go through the membrane more easily [27] Alternatively, a reduced charge repulsion between the negatively charged membrane and the negatively charged functional groups of the organics could decrease rejection as suggested by Schäfer [35]. Rejection is the HA, which has been repo greater than $2.5 \mathrm{mM} \mathrm{[20].} \mathrm{Coagulates} \mathrm{are} \mathrm{larger} \mathrm{and} \mathrm{more} \mathrm{retained} \mathrm{b}$ increase with time, partly due to an increase in the concentration of organics in the cell, and partly due to pore closure or blockage. No deposition on the membrane was detectable using DOC measurements and mass balance calculations.

Rejections measured with UV (Figure 2B) are in the range of 84 to $92 \%$, which is higher than rejection measured by DOC. This indicates selectivity towards the rejection of UV-absorbing molecules, which also tend to be larger and more aromatic [12]. Rejection is highest at $0.5 \mathrm{mM} \mathrm{Ca}$ and then drops and remains constant with increasing calcium concentration. Since the molecules detected by UV measurements are larger they may not reduce their size sufficiently to pass through the membrane.

The deposition of calcium on the membranes is tabulated in Table 3. The amount of calcium deposited increases with calcium concentration with the exeption of $4 \mathrm{mM}$ where no calcium deposition is apparent. This result was confirmed by a repeat experiment and may indicate a change in mechanism from deposition a of compounds in the membrane pores to coagulation which allows no further pore penetration with subsequent deposition due to size exclusion.

The 100kDa membrane shows very large flux decline with increasing calcium concentration (Figure 1), fluxes being reduced to $58 \%, 33 \%, 14 \%, 12 \%$ and $10 \%$ of the origint flux with $0.5,1.25,2.5$ (repeated) and $4 \mathrm{mM}$ calcium, respectively. Only 4 to $12 \%$ of flux could be restored after pure water was flushed through the membrane, indicating that fouling was mostly irreversible. This may be explained by the fact that pores are bigger and thus aggregates can penetrate into the pores and cause pore blocking. The molecules are too small to be retained effectively by the membrane if no aggregation occurs (compare Table 1 and 2). Experiments with both 2.5 and $4 \mathrm{mM}$ calcium added show that flux reaches a plateau value. This confirms the different configuration of HA molecules after $2.5 \mathrm{mM}$ calcium added. Releasing pressure and emptying the cell at the end of each cycle did not influence either fouling pattern, indicating irreversible fouling rather than concentration polarisation.

The mass balance of DOC confirmed these results, depositions were 5, 11, 15 and $14 \%$ at
polarisation. concentrations of $0.5,1.25,2.5$ and $4 \mathrm{mM}$ Ca (results not shown), respectively. This shows 
differences between adsorption onto the membrane surface, as typified by the $10 \mathrm{kDa}$ membrane (negligible deposition) and within the pores.

DOC rejection of the $100 \mathrm{kDa}$ membrane (Figure $2 \mathrm{C}$ ) was lower compared to the $10 \mathrm{kDa}$ membrane especially for 0.5 and $1.25 \mathrm{mM} \mathrm{Ca}$ where rejection was no higher than 7 and $15 \%$, respectively. However, there is a big difference with 2.5 and $4 \mathrm{mM} \mathrm{Ca}$, with a rejection of up to 65 and $74 \%$ (this latter value is comparable to what the $10 \mathrm{kDa}$ membrane achieved at $0.5 \mathrm{mM} \mathrm{Ca}$ ), respectively. This confirms the critical a cejection increased after each cycle indicating that dep por wister molecules. Deposition within the pores would decrease pore diameter and decrease the effective MWCO.

UV rejections (Figure 2D) confirm the results of DOC rejection. At 0.5 and $1.25 \mathrm{mM} \mathrm{Ca}$, both rejections are comparable and thus rejection was due only to big UV-absorbing molecules being retained by the membrane. There is also a big step for 2.5 and $4 \mathrm{mM} \mathrm{Ca}$, with rejections up to 66 and $82 \%$. This values are as much as $15 \%$ higher than for the DOC. This indicates that big, UVabsorbing coagulated molecules are selectively coagulated and thus retained.

The calcium deposition confirms the effect of organic coagulation, as deposition occurs only at calcium concentrations of 2.5 and $4 \mathrm{mM}$ (Table 3 ).

During these experiments the $100 \mathrm{kDa}$ membrane consistently exhibited flux decline depending on the filtration conditions, whereas the $10 \mathrm{kDa}$ membrane showed no such decline. Several factors could explain this

First of all, pore blocking could cause more severe flux decline of the $100 \mathrm{kDa}$ membrane. This is addressed in the blocking law analysis below.

Secondly, the high flux of this membrane could cause severe concentration polarisation and membrane-solute interaction, or fouling (thus reach a 'critical flux' where deposition starts to control flux). The concept of critical flux was introduced by Howell [37]. This effect can be controlled by variation of the transmembrane pressure and thus flux.

controlled by variation of the transmembrane pressure and thus flux.
Thirdly, the higher filtrate volumes used for this membrane could simply increase the cake mass Thirdly, the higher filtrate volumes used for this membrane could simply increase
and thus the resistance. The filtrate volume effect can also be examined very easily.

Figure 3 shows the flux of the $100 \mathrm{kDa}$ membrane at 8 and $100 \mathrm{kPa}$ and that of the $10 \mathrm{kDa}$ membrane at $300 \mathrm{kPa}$, but with a filtration volume identical to that of the $100 \mathrm{kDa}$ membrane. The results show that volume is not a critical parameter. The flux remains constant for the $10 \mathrm{kDa}$ membrane even at a filtrate volume comparable to that of the $100 \mathrm{kDa}$ membrane. The small filtrate volumes used in the experiments are thus an appropriate representative of flux decline.

Lower flux indeed decreased the amount of fouling by reducing possibly pore penetration and gel formation on the membrane. If the $100 \mathrm{kDa}$ membrane is operated at a lower pressure and therefore lower flux, the decline is reduced and the final value is identical, at a much lower pressure. This clearly indicates the importance of 'critical flux' and this requires further studies for surface water systems. Flux is obviously not proportional to pressure at these conditions (a pressure increase from 8 to $100 \mathrm{kPa}$ should cause a 12.5 fold flux increase).

To further investigate which fouling mechanism is operative, the filtration laws developed by Hermia [38] and explained in detail by Cheryan [39] and Bowen et al. [40] were applied. The equations are summarised in Table 4 and applied at $2.5 \mathrm{mM} \mathrm{Ca}$, with and without stirring for the $100 \mathrm{kD}$ m At this calcium concentration ageregation of the organics occurs. It should be noted that the blocking laws are only valid for unstirred filtration. For high permeate fluxes stirring noted that the blocking laws are only valid for unstirred filtration. For high permeate fluxes stirring may have a negligible effect.

These functions are plotted in Figure 4A (complete and cake filtration) and Figure 4B (intermediate and standard blocking). The results only show the first cycle of the recycle experiments. The analysis is not valid for the further cycles as the feed concentration varies if deposition occurs during the first cycle and filtration is not continuous.

The effect of stirring is large. This means that the blocking law analysis for these conditions is invalid. Initial fluxes were about $500 \mathrm{Lm}^{2} \mathrm{~h}^{-1}$ and fluxes after the first cycle were 346 and $152 \mathrm{Lm}$
${ }^{2} \mathrm{~h}^{-1}$ for stirred and unstirred conditions, respectively (this corresponds to flux declines of 40 and $70 \%)$

Neither the cake filtration nor the complete blocking law show a linear relationship when considering that the analysis is invalid for stirred filtration.

Intermediate blocking represents the sealing of pores by an accumulation of 'particles'. This relationship is not linear Standard blocking is the deposition of solute on the internal pore wats, inducing a reduction in pore diameter. This relationship is the only one which can be considered as linear over a considerable range.

This means that the blocking law analysis was successful in the distinction between pore and This means that the blocking law analysis was successful in the distinction between pore and
surface fouling. Pore fouling by a pore size reduction is the dominant mechanism for the $100 \mathrm{kDa}$ membrane as was suggested considering the pore size and the estimated size of organics after aggregation.

This study of the influence of calcium on the fouling and rejection characteristics of the UF membranes highlights several points. Rejections were higher than expected for both membranes, especially in the pros the $10 \mathrm{kDa}$ membrane. The $10 \mathrm{kDa}$ membrane results suggest that $\mathrm{HA}$ molecules tend to curl up at low salt concentration, and pass through the membrane more easily. Higher salt concentrations tend low salt concentration, and pass through the membrane more easily. Higher salt concentrations tend to destabilise the molecules, with IHSS HA coagulating around $2.5 \mathrm{mM}$. This increases rejection.
Although this had no influence on the flux for the $10 \mathrm{kDa}$ membrane, pore plugging occurred for the Although this had no influence on the flux for the $10 \mathrm{kDa}$ membrane, pore plugging occurred for the
$100 \mathrm{kDa}$ membrane, and this was detrimental to flux, with flux being lowered by $85 \%$. For this membrane, fouling was mostly irreversible.

This demonstrates that flux is a critical parameter in membrane fouling, along with the calcium concentration which appears to enhance aggregate formation.

\subsection{Effect of organic type}

The influence of organic type on flux decline and membrane rejection was studied for the six different organics, at a calcium concentration of $2.5 \mathrm{mM}$

The 10kDa membrane showed essentially no flux decline throughout the length of the experiments (Figure 5A). The flux for IHSS FA had a distinct tendency to rise, showing that this HS makes the membrane more hydrophilic. Elimelech reported a similar effect in nanofiltration [41]. Jucker and become more hydrophilic. The IHSS HA causes an apparently small decline to a flux ratio of about 0.95 . However, since the initial flux $\mathrm{J}_{0}$ for this membrane is low, it has a significant resistance and a $5 \%$ drop is equivalent to a $50 \%$ drop for the $100 \mathrm{kDa}$ membrane in terms of deposit resistance. DOC rejections (Figure 6A) show very distinct patterns for the different organics, which were repeatable over the range of permeate samples. Except for NOM, the trend in rejection corresponded to size (Table 2). The highest rejection was achieved for IHSS-HA, with 75\% DOC rejection. This was explained earlier to be due to coagulation of this HS. NOM-HA showed much lower rejection, with only $51 \%$ for the third permeate sample. The fractionation experiments [35] exhibited little wifference between the two HA; however, $10 \%$ of IHSS HA was in the >30kDa fraction whereas only $2 \%$ of NOM-HA was $>30 \mathrm{kDa}$ UV/DOC ratios (results not shown) also showed a UV content three times larger for IHSS HA than for NOM-HA. Therefore, IHSS HA has a greater tendency to coagulate with $2.5 \mathrm{mM}$ Ca added than NOM-HA. Both FA show similar rejections, of $45 \%$ for IHSS FA and $41 \%$ for NOM-FA. The difference in rejection between FA and HA shows that FA are much smaller than $\mathrm{HA}$, and that they do not coagulate at $2.5 \mathrm{mM} \mathrm{Ca}$. Indeed, FA are less hydrophobic than HA and very soluble. NOM-Hyd showed very little rejection (19\%), and this was predictable since it is very small [35] (see Table 2). NOM exhibits rejections higher than NOM-HA, NOM-FA or NOM-Hyd. This may be because NOM was partially undissolved, due to the presence of inorganics. Alternatively, the fractionation process (using XAD resins and 
extreme $\mathrm{pH}$ variations) may have somewhat modified the samples. This behaviour was also evident from the mass balance calculations, which showed higher deposition (6\% NOM was deposited on the membrane surface during ultrafiltration (results not shown)). While small amounts of HA or FA seem to deposit on the membrane, NOM-Hyd showed no deposition. For HA and FA, rejections increased during the experiment, showing that big molecules are retained first, followed by the smaller ones.

UV rejections (Figure 6B) confirm the above results. They are moderately higher than the DOC rejections (10 to $17 \%$ higher), again indicating selectivity towards the retention of large, UVabsorbing molecules.

For the 100kDa membrane, flux decline is shown in Figure 5B. The most severe flux decline was with IHSS HA for which flux ratio dropped to $14 \%$ and was only recovered to $18 \%$, exhibiting detrimental fouling of the $100 \mathrm{kDa}$ membrane, as described above. NOM-HA also showed significant flux decline, but flux ratio only dropped to 53\%. From such a difference, it can be concluded that it is the large UV-absorbing molecules that are responsible for flux decline. They are prone to coagulate, and to cause pore blocking. Both types of FA showed small flux declines, with flux rit $97 \%$ for IHSS FA and $73 \%$ for NOM-FA and this later flux was recovered to $91 \%$ flux ratios $97 \%$ ar after pure water flush. Moreover, it was noted that at the end of each cycle, the flux increased again This indicates that it is concentration polarisation that is responsible for flux decline, being mainly reversible. NOM-FA seems to be bigger and to interact more with calcium, thus causing more pore blocking. Concentration polarisation was even more visible for NOM-Hyd, with the flux ratio increasing after pressure release, and flux ratio, although lowered to $60 \%$ was recovered to $90 \%$. NOM, on the other hand, had a flux decline comparable to that of NOM-FA, being mostly constituted of this HS, but flux could not be recovered, indicating once again that the HA was responsible for irreversible fouling, while flux decline was linked to the concentration polarisation layer. Deposition of undissolved NOM might also be responsible for this flux decline.

Apart from IHSS HA, the rejection pattern of which was described earlier, rejections were very low, Apart from IHSS HA, the rejection pattern of which was described earlier, rejections were very low,
with no more than 10\% DOC rejection (Figure 6C). UV rejections (Figure 6D) showed the same with no more than $10 \%$ DOC
pattern as DOC rejection.

In conclusion, hydrophobic UV-absorbing molecules are responsible for irreversible pore adsorption and plugging, thus promoting detrimental flux decline, and high rejection. Pores were blocked less with NOM-HA, but flux decline was still irreversible. For both FA and NOM-Hyd, smaller molecules cause concentration polarisation, which is responsible for reversible flux decline. This phenomenon was greater for NOM-Hyd, which is also the smallest fraction of NOM. Comparison between NOM and its components indicated that flux decline was linked to Comparison between NOM and its components indicated that flux decline was linked to
concentration polarisation (due to the smallest molecules) and that irreversible fouling occurred concentration polarisation (due to the smallest
(due to pore blocking by the larger organics).

\section{Conclusions}

In this study, the fouling of UF membranes due to different organic fractions was studied. The use of two ultrafiltration membranes of different MWCO, $10 \mathrm{kDa}$ and $100 \mathrm{kDa}$, with different water of two ultrafilt permeabilies ( flux of $620 \pm 6$ gave high rejection and no flux decline, whereas the second one did not achieve good rejection results and experienced high flux decline.

The different behaviour was explained with a combination of a 'critical flux' effect and varied pore penetration due to the different pore diameters of the membranes and ability of the organics to form aggregates with calcium.

IHSS HA was found to coagulate with a calcium concentration larger than $2.5 \mathrm{mM}$. This caused pore adsorption and pore size reduction which was found to be detrimental to flux on the $100 \mathrm{kDa}$ membrane. The other organics studied were less rejected by the $10 \mathrm{kDa}$ membrane due to their smaller size. Both FA and the NOM-Hyd fraction experienced concentration polarisation, which was mainly reversible.

The results of this study show that characterisation of surface water composition (salt concentration, natural organic matter content), membrane operation parameters and characateristics and a good understanding of solute-solute interactions are critical in predicting ultrafiltration behaviour.

\section{Acknowledgements}

The CRC for Water Quality and Treatment is thanked for providing scholarships to E. Aoustin and A.I. Schäfer, and for project funding. The ENSCM, France, is acknowledged for supplying a trave scholarship to E. Aoustin. We also acknowledge the material support from Millipore, Australia. 


\section{References}

[1] G. Crozes, P. White, M. Marshall, Journal AWWA, (Jan 1995) 78-89.

F.J. Stevenson, Humus Chemistry, Wiley, New York, 1982, 337-354

F.M. Thurman, Organic Geochemistry of Natural Waters, Martinus Nijhoff/Dr W. Junk Publishers, Dordrecht, 1985.

[4] G.R. Aiken, D.M. McKnight, R.L. Wershaw, P. MacCarthy, Humic Substances, in Soil, G.R. Aiken, D.M. McKnight, R.L. Wershaw, P. Macc

Sediment, and Water, John Wiley \& Sons, Inc., 1985.

[5] C. Jucker, M.M. Clark, Journal of Membrane Science, 97 (1994) 37-52.

[6] Averett R.C., Leenheer J.A., McKnight D.M., Thorn K.A., U.S. Geological Survey (1989) Open-File Report 87-557.

[7] E.M. Thurman, R.L. Wershaw, R.L. Malcom and D.J. Pinckney, Org. Geochem., 4 (1982) 27-35.

[8] K. Ghosh, and M. Schnitzer 129, 5 (1980) 266-276.

[9] M.H.B. Hayes, P. McCarthy, R.L. Malcom and R.S. Swift (Eds.), Humic Substances II M.H.B. Hayes, P. McCarhy, R.L. Malce

[10] B. Aster, P. Burba, J.A.C. Broekaert, Fresenius Journal of Analytical Chemistry 354 B. Aster, P. Burbar
(1996) $722-728$.

[11] M. Schnitzer and S.U. Khan, Humic Substances in the Environment, Dekker, New York, 1972.

[12] B. Martin-Mousset, J.P. Croue, E. Lefebvre and B. Legube, Water Research, 31, 3, (1997) 541-553.

E. Tipping, M. Ohnstad, Chemical Geology, 44 (1984) 349-357.

C. Staub, J. Buffle, W. Haerdi, Analytical Chemistry, 56 (1984) 2843-2849.

I.L. Küchler, N. Miekeley, The Science of the Total Environment, 154 (1994) 23-28.

A. Maartens, P. Swart, E.P. Jacobs, Desalination, 115 (1998) 215-227.

M.R. Hoffmann, E.C. Yost, S.J. Eisenreich, W.J. Maier, Environmental Science \& Technology, 15, 6 (1981) 655-661.

[18] K.J. Kim, A.G. Fane, C.J.D. Fell and D.C. Joy, Journal of Membrane Science, 68 (1992) 79-91.

[19] P.K. Cornel, R.S. Summers, P.V. Roberts, Journal of Colloid and Interface Science, 110, $1,(1986)$ 149-164.

[20] M.A. Cohen-Stuart, G.J. Fleer, J. Lyklema, W. Norde and J.M.H.M. Scheutjens, Advances in Colloid and Interface Science, 34 (1991) 477-535.

[21] A.I. Schäfer, A.G. Fane, T.D. Waite, Desalination, 108 (1998) 109-122.

[22] F.A. Bonner, J.L. Bersillon, C.R. O'Melia, paper presented at the American Water Works Association Annual Conference, Vancouver, June 18-22, 1992.

[23] A.J.B van Boxtel, Z.E.H. Otten and H.J.L.J. van der Linden, Journal of Membrane Science, 58, (1991) 89-111.

[24] J.M. Laîné, J.P. Hagstrom, M.M. Clark and J. Mallevialle, Journal AWWA, 81 (11) (1989) 61-67.

[25] G. Crozes, C. Anselme, J. Mallevialle, Journal of Membrane Science, 84 (1993) 61-77.

[26] J.A. Nilson, F.A. DiGiano, Journal AWWA, (May 96) 53-66.

[27] G. Crozes, J. Jacangelo, C. Anselme, J.-M. Laîné, (1995), Proc. AWWA Membrane

Technology Conference, Reno, Nevada (Aug 95) 457-485.
Y. Chang, M.M. Benjamin (1996), Journal AWWA (Dec 96) 74-88.

[29] V. Lahoussine-Turcaud, Journal of Membrane Science, 52 (1990) 173-190.

[30] V. Ravindran, B.N. Badriyha (1993), Proc. of AWWA Membrane Technology Conference, Baltimore (Aug 93) 587-599.

[31] J.-M. Laîné, M.M. Clark, J. Mallevialle, Journal AWWA (Dec 90) 82-87.
[32] M.M. Clark, C. Jucker, Proc. of AWWA Membrane Technology Conference, Baltimore, (Aug 93) 259-272.

[33] A. Suki, A.G. Fane and C.J.D. Fell, J. Membrane Science, 21 (1984) 269-283.

[34] E.Worch, Vom Wasser, 81, 289-297.

[35] A.I. Schäfer, Natural Organics Removal using Membranes, PhD Thesis, UNSW, Chemical Engineering, Sydney (1999).

A. Eaton, Journal AWWA (Feb 95) 86-90.

[36]

[37] J.A. Howell, Journal of Membrane Science,

[39] Ultrafiltration and Microfiltration Handbook, M. Cheryan, pp.243-244.

[40] W.R. Bowen, J.I. Calvo, Hernandez A., Journal of Membrane Science, 101 (1995) 153165.

[41] M. Elimelech, X. Zhu, A.E. Childress and S. Hong, Journal of Membrane Science, 127 (1997) 101-109. 
Aoustin, E. ; Schäfer, A.I. ; Fane, A.G. ; Waite, T.D. (2001) Ultrafiltration of Natural Organic Matter, Separation and Purification Technology, 22-23, 63-78 doi:10.1016/S1383-5866(00)00143-X

\section{Figure captions}

FIGURE 1: Influence of Ca concentration on flux decline.

Flux as a function of calcium concentration, at $\mathrm{pH}=7-8$, with $12.5 \mathrm{mgL}^{-1}$ as DOC IHSS HA as DOC in background solution, for increasing calcium concentrations for the $10 \mathrm{kDa}$ and $100 \mathrm{kDa}$ membranes. PWF is the pure water flux of the membrane.

FIGURE 2: Influence of Ca concentration on IHSS HA rejection. IHSS HA rejection as a function of calcium concentration for the $10 \mathrm{kDa}$ membrane (A) as DOC
and (B) as UV absorbance at $254 \mathrm{~nm}$, and for the $100 \mathrm{kDa}$ membrane (C) as DOC and (D) as UV (2.5 mM CaCl $2, \mathrm{pH} 7-8$ and $12.5 \mathrm{mgL}^{-1}$ as DOC IHSS HA). The experiment for $2.5 \mathrm{mM}$ Ca was repeated.

FIGURE 3: Effect of transmembrane pressure and filtrate volume.

Comparison of transmembrane pressure or initial flux for 10 and $100 \mathrm{kDa}$ at identical filtrate volumes (2.5 $\mathrm{mM} \mathrm{CaCl}_{2}, \mathrm{pH} 7-8$ and $12.5 \mathrm{mgL}^{-1}$ as DOC IHSS HA).

\section{FIGURE 4: Filtration law analysis.}

(A) Complete blocking and cake filtration analysis and (B) intermediate and standard blocking analysis for the $100 \mathrm{kDa}$ membrane at $2.5 \mathrm{mM} \mathrm{CaCl}_{2}, \mathrm{pH} 7-8$ and $12.5 \mathrm{mgL}^{-1}$ as DOC IHSS HA at stirred $(270 \mathrm{rpm})$ and unstirred conditions.

\section{FIGURE 5: Influence of organic type on flux decline.}

Flux ratio as a function of permeate volume for different organic types (A) for the $10 \mathrm{kDa}$ membrane and (B) for the $100 \mathrm{kDa}^{2}$ membrane $\left(2.5 \mathrm{mM} \mathrm{CaCl}_{2}, \mathrm{pH} 7-8\right.$ and $12.5 \mathrm{mgL}^{-1}$ as DOC IHSS HA). Experiment for IHSS HA and 100kDa membrane was repeated.

\section{FIGURE 6: Influence of organic type on rejection.}

Organic rejection as a function of organic type for the $10 \mathrm{kDa}$ membrane (A) as DOC and (B) as UV absorbance at $254 \mathrm{~nm}$, and for the $100 \mathrm{kDa}$ membrane (C) as DOC and (D) as UV $(2.5 \mathrm{mM} \mathrm{CaCl}$, $\mathrm{pH} 7-8$ and $12.5 \mathrm{mgL}^{-1}$ as DOC IHSS HA). Experiment for IHSS HA and 100kDa membrane was repeated.

\section{Tables}

TABLE 1: Pore size, pure water flux and surface charge of the membranes [35].

\begin{tabular}{lcc}
\hline Parameter & PLGC & PLHK \\
\hline MWCO (kDa) & 10 & 100 \\
Pore Diameter (nm) & 5.2 & 18.2 \\
Membrane Zeta Potential (mV) & & \\
$\quad$ pH 3 & 0 & -3 \\
$\quad$ pH 7 & -7.5 & -16 \\
$\quad$ pH 12 & -7.5 & -19 \\
Operating Pressure (kPa) & 300 & 100 \\
Average Pure Water Flux $\left(\mathrm{Lm}^{-2} \mathrm{~h}^{-1}\right)$ & $46 \pm 5$ & $620 \pm 68$ \\
Clean Water Permeability $\left(\mathrm{Lm}^{-2} \mathrm{~h}^{-1} \mathrm{bar}^{-1}\right)$ & 21.7 & 1320 \\
Clean Membrane Resistance $\left(\mathrm{m}^{-1}\right)$ & $1.66 \cdot 10^{10}$ & $0.03 \cdot 10^{10}$ \\
\hline
\end{tabular}

TABLE 2: MW and size of the different HS and NOM [35].

\begin{tabular}{lcc}
\hline Organic Type & $\mathrm{M}_{\mathrm{w}}\left(\mathrm{gmol}^{-1}\right)$ & Molecule Diameter $(\mathrm{nm})$ \\
\hline IHSS HA & 2748 & 2.70 \\
IHSS FA & 1532 & 1.98 \\
NOM & 1381 & 1.88 \\
NOM HA Fraction & 1857 & 2.20 \\
NOM FA Fraction & 1318 & 1.84 \\
NOM Hydrophilic Fraction & 970 & 1.56 \\
\hline
\end{tabular}


Aoustin, E. ; Schäfer, A.I. ; Fane, A.G. ; Waite, T.D. (2001) Ultrafiltration of Natural Organic Matter, Separation and Purification Technology, 22-23, 63-78 doi:10.1016/S1383-5866(00)00143-X

\section{TABLE 3: Calcium deposition as a function of calcium concentration and organic type.}

\begin{tabular}{lccc}
\hline Organic Type & $\begin{array}{c}\text { Calcium } \\
\text { Concentration } \\
(\mathrm{mM})\end{array}$ & $10 \mathrm{kDa}$ & $100 \mathrm{kDa}$ \\
\hline IHSS HA & 0.50 & $5.6(0.3)$ & 0 \\
& 1.25 & $5.5(0.7)$ & 0 \\
& 2.50 & $6.2(1.6)$ & $15(3.5)$ \\
& 4.00 & 0 & $13(10.2)$ \\
\hline IHSS FA & 2.50 & 0 & $14.2(6.0)$ \\
NOM & 2.50 & $1.6(0.4)$ & $1.4(0.8)$ \\
NOM HA Fraction & 2.50 & $5.0(1.3)$ & $20.5(12.6)$ \\
NOM FA Fraction & 2.50 & - & $13.2(6.6)$ \\
NOM Hydrophilic Fraction & 2.50 & $1.5(0.5)$ & $0.4(0.2)$ \\
\hline
\end{tabular}

\section{TABLE 4: Constant Pressure Filtration Laws [38, 40].}

\begin{tabular}{|c|c|c|}
\hline Law & Equation & Description \\
\hline $\begin{array}{l}\text { Complete Blocking } \\
\text { (pore blocking) }\end{array}$ & $V=\frac{J_{0}}{k_{C B}}\left(1-e^{-k_{C B} t}\right)$ & $\begin{array}{l}\text { Particles do not accumulate on each other and } \\
\text { particles arriving at the membrane will seal } \\
\text { pores, } d_{\text {particle_}} d_{\text {pore }}\end{array}$ \\
\hline $\begin{array}{l}\text { Intermediate Blocking } \\
\text { (long term adsorption) }\end{array}$ & $V=\frac{J_{0}}{k_{I B}} \ln \left(1+k_{I B} t\right)$ & $\begin{array}{l}\text { Particles do accumulate on each other and seal } \\
\text { membrane pores, } d_{\text {particle }} d_{\text {pore }}\end{array}$ \\
\hline $\begin{array}{l}\text { Standard Blocking } \\
\text { (direct adsorption) }\end{array}$ & $\frac{t}{V}=\frac{1}{J_{0}}+\frac{k_{S B}}{J_{0}} t$ & $\begin{array}{l}\text { Particles deposit on the internal pore walls, } \\
\text { decreasing the pore diameter, } d_{\text {particle }}<<d_{\text {pore }}\end{array}$ \\
\hline $\begin{array}{l}\text { Cake Filtration } \\
\text { (boundary layer } \\
\text { resistance) }\end{array}$ & $\frac{t}{V}=\frac{k_{C F}}{4 J_{0}^{2}} V+\frac{1}{J_{0}}$ & $\begin{array}{l}\text { Particles are retained due to sieving and form a } \\
\text { cake on the surface, deposition occurs on other } \\
\text { particles, all membrane area is already } \\
\text { blocked, } d_{\text {particle }}>d_{\text {pore }}\end{array}$ \\
\hline
\end{tabular}

Figure 1

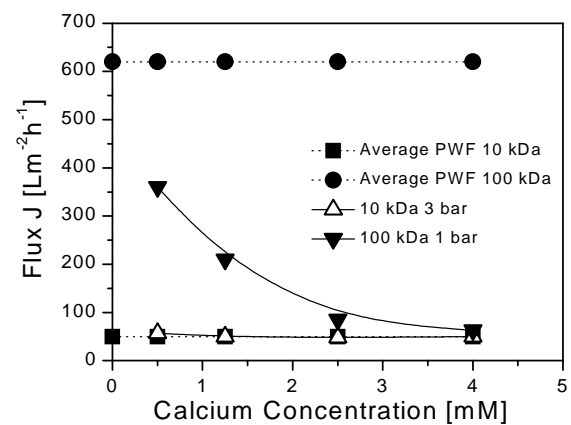


Aoustin, E. ; Schäfer A.I. ; Fane, A.G. ; Waite, T.D. (2001) Ultrafiltration of Natural Organic Matter, Separation and Purification Technology, 22-23, 63-78 doi:10.1016/S1383-5866(00)00143-X

Figure 2
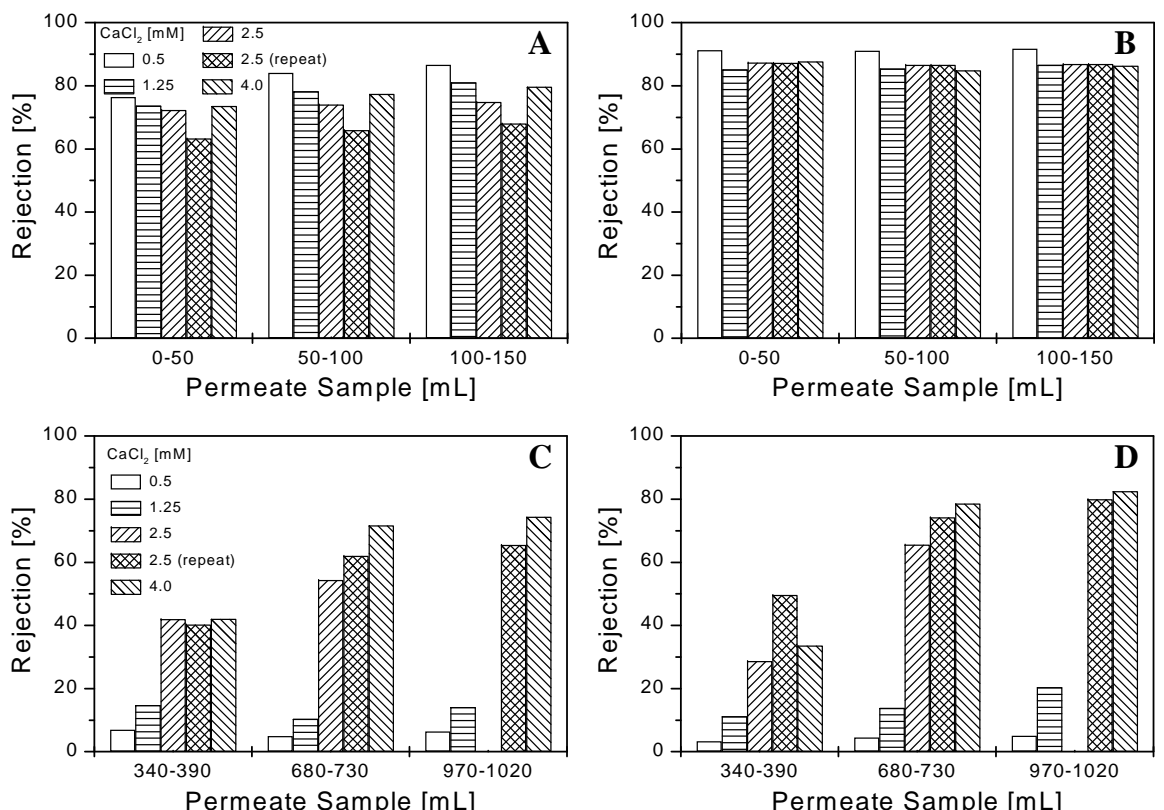

Figure 3

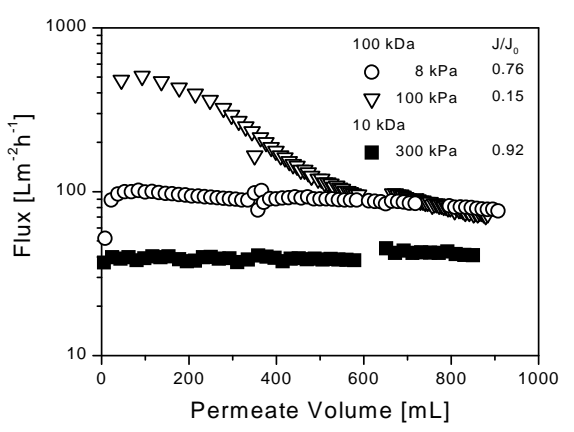

Figure 4
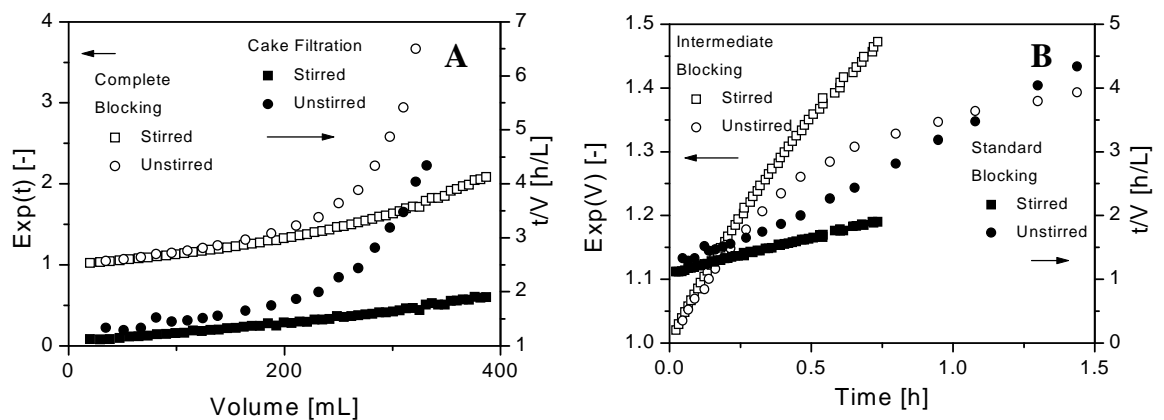
Aoustin, E. ; Schäfer, A.I. ; Fane, A.G. ; Waite, T.D. (2001) Ultrafiltration of Natural Organic Matter, Separation and Purification Technology, 22-23, 63-78 doi:10.1016/S1383-5866(00)00143-X

Figure 5
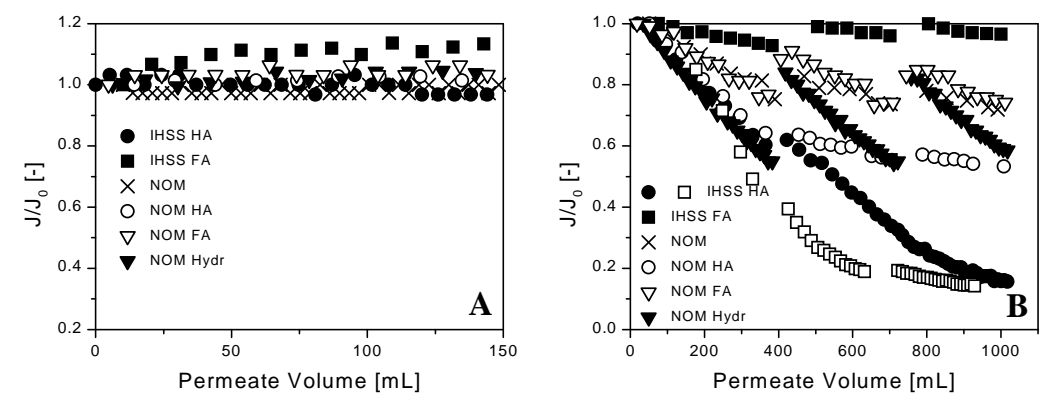

Figure 6
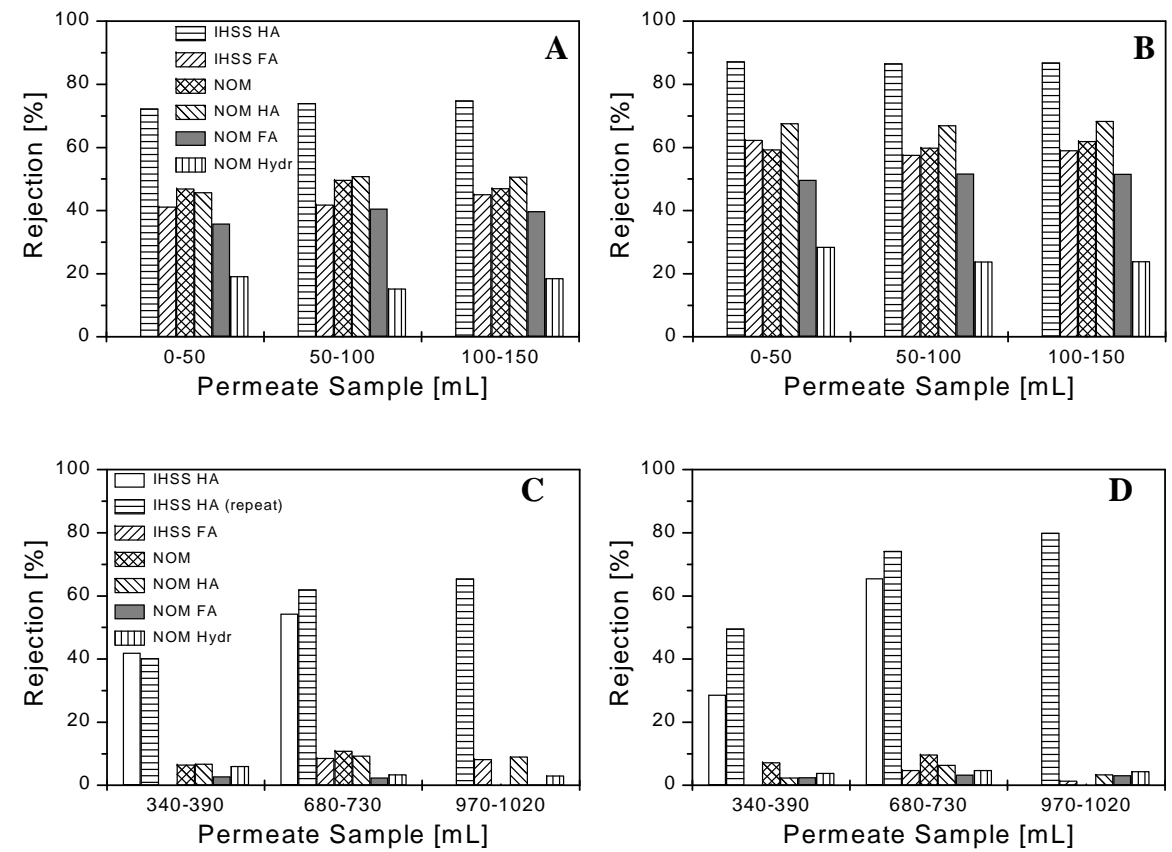